\title{
THE RELATIONSHIP BETWEEN KNOWLEDGE AND ATTITUDE TOWARD ANEMIA ON PREGNANCY IN LIMBOTO HEALTH CENTRE
}

\author{
Zuriati Muhamad \\ Program Studi DIV Bidan Pendidik, Fakultas IImu Kesehatan \\ Universitas Muhammadiyah Gorontalo, Indonesia \\ Jl. Prof. Dr. Mansoer Pateda, Pentadio Timur, Gorontalo, Indonesia 96212 \\ Co- author : zuriatimuhamad@umgo.ac.id
}

\begin{abstract}
Anemia in pregnancy is a national problem because it reflects the value of the socioeconomic welfare of the community, and its influence is very large on the quality of human resources This research was conducted at Puskesmas Limboto. The purpose of this research is to findout the correlation of knowledge and attitude of Primigravida Pregnant Women with Anemia at Limboto Puskesmas Kabuapten Gorontalo. The type of this research is Descriptive Analytic with cross sectional approach with sample number 48 respondents. The sampling technique used is purposive sampling. From result of analysis of SPSS 16 statistical test of knowledge with anemia using Chi-square formula with significance level 0,05 obtained result $0.013<0,05$ which mean there is correlation of knowledge with anemia at Puskesmas Limboto Kabupaten Gorontalo. As well as attitudes with anemia obtained results $0.000<0.05$ which means there is a correlationbetween attitude with anemia in the Work Area Puskesmas Limboto, Gorontalo District.
\end{abstract}

\section{Keywords: Knowledge, Attitude, Primigravida, Anemia}

\section{Abstrak}

Anemia pada kehamilan merupakan masalah nasional karena mencerminkan nilai kesejahteraan sosial ekonomi masyarakat, dan pengaruhnya sangat besar terhadap kualitas sumber daya manusia. Penelitian ini dilakukan Puskesmas Limboto.Tujuan penelitian ini untuk mengetahui hubungan pengetahuan dan sikap ibu hamil primigravida dengan kejadian anemia di wilayah Puskesmas Limboto Kabupaten Gorontalo. Desain penelitian ini ini menggunakan kuantitatif dengan pendekatan cross sectional dengan jumlah sampel 48 responden. Teknik pengambilan sampel yang digunakan adalah purposive sampling. Hasil analisis uji statistik menunjukkan hubungan antara pengetahuan dengan kejadian anemia menggunakan rumus Chisquare dengan tingkat kemaknaan 0,05 diperoleh hasil $0.013<0,05$ yang berarti ada hubungan antara pengetahuan dengan kejadian anemia di Wilayah Puskesmas Limboto Kabupaten Gorontalo. Serta ada hubungan antara sikap dengan kejadian anemia diperoleh hasil $0.000<0,05$.

Kata Kunci: Pengetahuan, Sikap, Primigravida, Anemia 


\section{PENDAHULUAN}

Anemia adalah suatu kondisi medis dimana jumlah sel darah merah atau hemoglobin kurang dari normal.Kadar hemoglobin normal umumnya berbeda pada laki-laki dan perempuan. Untuk pria, anemia biasanya didefinisikan sebagai kadar hemoglobin kurang dari 13,5 gram/100ml dan pada wanita sebagai hemoglobin kurang dari 12,0 gram/100m (Angrainy, 2017).

Anemia pada kehamilan merupakan masalah nasional karena mencerminkan nilai kesejahteraan sosial ekonomi masyarakat, dan pengaruhnya sangat besar terhadap kualitas sumber daya manusia.Anemia kehamilan disebut "potential danger to mother and child" (potensi membahayakan ibu dan anak), karena itulah anemia memerlukan perhatian serius dari semua pihak yang terkait dalam pelayanan kesehatan (Wedyareni, 2015).

Penyebab terbesar kematian ibu di Indonesia pada tahun 2010-2013 masih tetap sama yaitu perdarahan. Sedangkan partus lama merupakan penyumbang kematian ibu terendah. Sementara itu penyebab lain-lain juga berperan cukup besar dalam menyebabkan kematian ibu, yang dimaksud penyebab lain-lain adalah penyebab kematian ibu secara tidak langsung, seperti kondisi penyakit kanker, ginjal, jantung, tuberkolosis atau penyakit lain yang diderita ibu (Infodatin dalam Kinanthi, 2016). Perdarahan merupakan faktor terbesar penyebab tingginya AKI.Salah satu faktor risiko utama terjadinya perdarahan adalah anemia.Angka Kematian Ibu (AKI) merupakan salah satu indikator kesehatan ibu yang masih tinggi di Indonesia bila di bandingkan dengan AKI di negara ASEAN lainnya.Menurut SDKI tahun 2007, AKI di Indonesia yaitu 228 per 100.000 kelahiran hidup. Adapun faktor penyebab langsung kematian ibu adalah perdarahan 35,63\% preeklamsia dan eklamsia $20,12 \%$, infeksi $20,7 \%$ dan komplikasi abortus 20,84\% (Ibrahim dalam Angrainy, 2017).

Prevalensi anemia menyerang lebih dari 2 milyar penduduk dunia.Di negara berkembang terdapat 370 juta wanita yang menderita anemia.Rata-rata lebih tinggi pada ibu hamil (51\%), wanita tidak hamil (41\%).Di India terdapat sekitar (88\%) ibu hamil yang menderita anemia, di Asia ditemukan (60\%) wanita yang mengalami anemia (Gibney dalam Yuwono, 2013).

Menurut World Health Organization (WHO) memperkirakan bahwa 35 - $75 \%$ ibu hamil di 
Negara berkembang dan $18 \%$ ibu hamil di Negara maju mengalami anemia. Namun banyak diantara mereka yang telah menderita anemia pada saat konsepsi, dengan perkiraan prevelensi sebesar $43 \%$ pada perempuan yang tidak hamil di Negara berkembang dan12 \% di Negara yang lebih maju (Prawirohardjo, 2014). Data dinas kesehatan Republik Indonesia (SDKI) menyebutkan bahwa ibu hamil yang terkena anemia mencapai $40 \%-50 \%$ yang artinya 5 dari 10 ibu hamil mengalami anemia (Lalage dalam Dewi, 2017).

Berdasarkan Riskesdas dalam Dewi (2016), terdapat $37,1 \%$ ibu hamil anemia, yaitu ibu hamil dengan kadar $\mathrm{Hb}$ kurang dari 11,0 gram/dl, dengan proporsi yang hampir sama antara di kawasan perkotaan $(36,4 \%)$ dan perdesaan $(37,8 \%)$. AKI di Kabupaten Gorontalo tahun 2014 sebanyak $\quad 235 / 100.000 \mathrm{KH} \quad(15$ orang), pada tahun 2015 ssebanyak 298/100.000 KH (20 orang) dan pada tahun 2017 sebanyak 257.2/100.000 KH (17 orang). Penyebab kematian ibu disebabkan beberapa faktor yaitu perdarahan, hipertensi dalam kehamilan, infrksi dan penyebab lainnya. Berdasarkan data ibu hamil anemia Puskesmas Limboto Kabupaten Gorontalo tahun 2017 bulan Februari sampai bulan Juli yaitu Februari 4 orang, Maret 29 orang, April 92 orang, Mei 17 orang, Juni 18 orang dan Juli 8 orang.

Anemia dalam kehamilan dapat menyebabkan dampak yang membahayakan bagi ibu dan janin. Anemia pada ibu hamil dapat meningkatkan resiko terjadinya perdarahan post partum. Anemia yang terjadi sejak awal kehamilan dapat menyebabkan resiko terjadinya prematur (Mochtar dalam Astuti, 2016). Adapun dampak lain dari anemia pada wanita hamil antara lain dapat terjadi abortus, persalinan prematurus, mudah terjadi infeksi, perdarahan antepartum, dan ketubanpecah dini (KPD), hambatan tumbuh kembang janin dalam rahim, hiperemesis gravidarum.

Sedangkan dampak padajanin dapat menyebabkan abortus, terjadi kematian intrauterin, persalinan prematuritas tinggi, berat badan lahir rendah, kelahiran dengan anemia, dan cacat bawaan(Manuaba dalam Wedyareni, 2015).

Penyebab paling umum dari anemia pada kehamilan adalah kekurangan zat besi. Hal ini penting dilakukan pemeriksaan anemia pada kunjungan pertama kehamilan. Bahkan jika tidak mengalami anemia pada saat kunjungan pertama, masih mungkin terjadi anemia pada kehamilan lanjutannya (Angriany, 2017). 
Upaya penanggulangan anemia telah banyak dilakukan tetapi belum menunjukkan penurunan yang berarti. Hal ini dimungkinkan karena sebagian besar ibu belum menyadari pentingnya pencegahan anemia serta bahaya yang akan ditimbulkan. Salah satu penanganannya adalah perlu melakukan analisis cermat perubahan perilaku pada sasaran yang lebih dini, yaitu penilaian tiga bentuk operasional perilaku berupa pengetahuan, sikap dan praktek yang ada di masyarakat (BKKBN dalam Kartikasari, 2010).

Berdasarkan penelitian Angrainy yang dilakukan di Puskesmas Rumbai Bukit pada tahun 2017 dengan judul "Hubungan Pengetahuan Dengan Sikap Ibu Hamil Dalam Pencegahan Anemia Di Puskesmas Rumbai" dan hasil penelitian lebih dari separuh responden berumur 20-35 tahun sebanyak 51 orang $(94,40 \%)$, sebagian besar responden berpendidikan SMP sebanyak 21 orang $(38,90 \%)$ dan lebih dari separuh responden tidak bekerja sebanyak 47 orang $(87,00 \%)$. Lebih dari separuh responden memiliki pengetahuan kurang terhadap pencegahan anemia sebanyak 32 orang $(59,30 \%)$, berpengetahuan cukup sebanyak 18 orang $(33,30 \%)$ dan sebanyak 4 orang $(7,40 \%)$ responden berpengetahuan baik.
Mayoritas responden yang melakukan sikap negatif dalam pencegahan anemia kehamilan sebanyak 42 orang $(83,40 \%)$. Ada hubungan yang signifikan antara pengetahuan dengan sikap pencegahan anemia kehamilan.

Dan pada penelitian yang dilakukan Astuti di wilayah kerja Puskesmas undaan Kabupaten Kudus tahun 2016 dengan judul "Faktor Yang Berhubungan Dengan Kejadian Anemia Pada Ibu Hamil Di Puskesmas Undaan Lor Kabupaten Kudus" di peroleh hasil penelitian bahwa faktor yang paling berpengaruh terhadap kejadian anemia pada ibu hamil adalah kepatuhan minum tablet $\mathrm{Fe}(\mathrm{OR}=$ $14,857, p=0,000$ ) artinya bahwa semakin patuh dalam minum tablet Fe yang mempunyai kemungkinan 14,857 kali pengaruh terhadap tidak terjadi anemia dibandingkan dengan yang tidak patuh dalam minum tablet Fe. Faktor- faktor yang berhubungan secara signifikan terhadap kejadian anemia pada ibu hamil yaitu umur, pendidikan dan kepatuhan mengkonsumsi tablet Fe. Sedangkan Faktor-faktor yang tidak berhubungan secara signifikan terhadap kejadian anemia pada ibu hamil adalah paritas.

Pemerintah telah melakukan berbagai upaya untuk menurunkan angka kejadian anemia pada ibu 
hamil dengan meningkatkan cakupan pemberian tablet Fe kepada ibu hamil secara gratis. Selain itu, pemerintah berupaya untuk melakukan penyuluhan tentang konsumsi tablet $\mathrm{Fe}$ dan anemia dalam kehamilan kepada ibu hamil, suami dan keluarga baik itu secara lisan pada saat kunjungan ANC, maupun melalui media cetak dan media elektronik. Pemerintah juga telah berupaya untuk melakukan pemeriksaan kadar $\mathrm{Hb}$ ibu hamil pada saat trimester pertama dan trimester ketiga yang bertujuan untuk memantau kadar $\mathrm{Hb}$ pada ibu hamil agar sedini mungkin terhindar dari anemia (Yuwono, 2013).

Bidan sebagai tenaga kesehatan berperan penting dalam mengatasi masalah anemia. Upaya yang dilakukan oleh bidan yaitu dengan memberikan Komunikasi, Informasi dan Motivasi (KIM) kepada ibu hamil tentang bahaya anemia, pentingnya tambahan zat besi, pentingnya peningkatan kesehatan, peningkatan kunjungan Antennal Care (ANC), sehingga anemia secara dini dapat diketahui dan diatasi (Manuaba dalam Yuwono, 2013).

Berdasarkan studi pendahuluan yang dilakukan di Puskesmas Limboto Kabupaten Gorontalo pada buku registrasi ibu hamil tahun 2017 bulan Januari-Juni 2017 sebanyak 216 ibu hamil dengan rata-rata kunjungan ibu hamil primigravida sebanyak 38 ibu hamil perbulan. Dari hasil wawancara dari 10 ibu hamil primigravida tentang anemia, sebanyak 3 ibu hamil (30\%) mengetahui tentang anemia dan sebanyak 7 ibu hamil (70\%) kurang mengetahui anemia pada kehamilan.

Berdasarkan latar belakang diatas, bahwa anemia merupakan penyebab utama kematian ibu. Maka, penulis tertarik melakukan penelitian mengenai "Hubungan Pengetahuan dan Sikap lbu Hamil Primigravida dengan Anemia di Wilayah Puskesmas Limboto Kabupaten Gorontalo".

\section{METODE PENELITIAN}

Penelitian ini menggunakan desain penelitian kuantitatif dengan pendekatan cross sectional, yang merupakan rancangan penelitian dengan melakukan pengukuran variabel pada saat itu. Penelitian yang diarahkan mencari pengaruh atau hubungan antara variabel independen dan dependen. kata saat itu di sini bukan merupakan semua subjek diamati tetap pada waktu yang sama, tetapi artinya tiap subjek hanya dilakukan satu kali saja dan pengukuran variabel subjek dilakukan pada pemeriksaan tersebut (Notoatmodjo, 2012). 
Penelitian ini telah dilaksanakan di Puskesmas Global Limboto Kabupaten Gorontalo pada tanggal 04 Oktober - 15 November tahun 2017. Populasi dalam penelitian ini adalah 55 ibu hamil di Wilayah Kerja Puskesmas Global Limboto. Tekhnik pengambilan sampel yaitu 48 ibu hamil dengan menggunakan purposive sampling.

\section{HASIL DAN PEMBAHASAN}

Univariat

Berdasarkan Tabel 1 di atas, diperoleh umur responden terbanyak yaitu pada umur 20 sampai 35 tahun sebanyak 35 orang $(72.9 \%)$ dan umur yang terendah adalah umur $<20$ tahun sebanyak 5 orang (10.4\%).

Berdasarkan Tabel 2 di atas, diperoleh tingkat pendidikan terbanyak yaitu tamat SMP sebanyak 20 responden (41.7\%) dan yang terndah yaitu tingkat pendidikan SI sebanyak 3 orang (6.2\%) dari 48 responden.

Berdasarkan Tabel 3 diatas, diperoleh tingkat pengetahuan terbanyak yaitu ibu hamil yang berpengetahuan yang kurang sebanyak 17 responden $(35,4 \%)$ dan yang terendah yaitu tingkat pengetahuan baik sebanyak 15 orang $(31,2 \%)$ dari 48 responden
Tabel 1

Distribusi Ferkuensi

Responden Berdasarkan Umur

\begin{tabular}{ccc}
\hline Umur (Tahun) & $\mathrm{F}$ & $\%$ \\
\hline$<20$ & 5 & 10.4 \\
$20-35$ & 135 & 72.9 \\
$>35$ & 8 & 16.7 \\
\hline Jumlah & 48 & 100 \\
\hline
\end{tabular}

Sumber : Data primer (2017)

Tabel 2. Distribusi

Frekuensi Responden Menurut Tingkat Pendidikan

$$
\text { Tingkta }
$$

$\mathrm{F} \quad \%$

Pendidikan

\begin{tabular}{ccc}
\hline SD & 19 & 39,6 \\
SMP & 20 & 41.7 \\
SMA & 6 & 12.5 \\
SI & 3 & 6.2 \\
\hline Jumlah & 48 & 100 \\
\hline
\end{tabular}

Sumber : Data primer (2017)

Tabel 3. Distribusi

Frekuensi Responden Menurut Pengetahuan

\begin{tabular}{|c|c|c|}
\hline Kategori & $\mathrm{F}$ & $\%$ \\
\hline Kurang & 17 & 35.4 \\
\hline Cukup & 16 & 33.3 \\
\hline Baik & 15 & 31.2 \\
\hline Jumlah & 48 & 100 \\
\hline \multicolumn{3}{|c|}{ Sumber : Data primer (2017) } \\
\hline \multicolumn{3}{|c|}{ Responden Menurut Sikap } \\
\hline Kategori & $\mathrm{F}$ & $\%$ \\
\hline Negatif & 27 & 56.2 \\
\hline Fositif & 21 & 43.8 \\
\hline Jumlah & 48 & 100 \\
\hline
\end{tabular}

Sumber : Data primer (2017) 
Tabel 5. Distribusi

Frekuensi Responden Menurut Sikap

\begin{tabular}{ccc}
\hline Kategori & $\mathrm{F}$ & $\%$ \\
\hline Tidak Anemia & 32 & 66.7 \\
Anemia & 16 & 33.3 \\
\hline Jumlah & 48 & 100 \\
\hline
\end{tabular}

Sumber : Data primer (2017)

Berdasarkan Tabel 4 diatas, diperoleh sikap terbanyak yaitu ibu hamil yang memiliki sikap negatif sebanyak 27 orang $(56,2 \%)$ dan yang terendah yaitu ibu hamil yang memiliki sikap positif sebanyak 21 orang $(43,8 \%)$ dari 48 responden.

Berdasarkan Tabel 5 diatas, diperoleh ibu hamil yang tidak Mengalami anemia sebanyak 32 responden $(66,7 \%)$ dan yang mengalami anemia yaitu sebanyak 16 orang $(33,3 \%)$ dari 48 responden.

yang tidak anemia dan berpengetahuan kurang sebanyak 11 orang $(22,9 \%)$ cukup 7 orang $(14,6 \%)$ dan berpengetahuan baik 14 orang $(29,2 \%)$ dan ibu hamil anemia yang memiliki pengetahuan kurang sebanyak 6 orang (12,5\%), cukup 9 orang $(18,8 \%)$, baik 1 orang $(2,1 \%)$. Dalam hal ini masih ada ibu yang tidak mengetahui tentang anemia hal ini disebabkan rendahnya pendidikan ibu serta ibu yang kurang memiliki informasi tentang anemia.Dari hasil analisis uji statistik SPSS 16 menggunakan rumus Chi-square dengan tingkat kemaknaan 0,05 diperoleh hasil $0.013<0,05$ yang berarti ada hubungan pengetahuan denga anemia di Wilayah Puskesmas Limboto Kabupaten Gorontalo.

Berdasarkan hasil penelitian pada tabel 7 di dapatkan hasil ibu hamil

Tabel 7.Hubungan Pengetahuan Ibu Hamil Dengan Anemia

\begin{tabular}{|c|c|c|c|c|c|c|c|c|c|}
\hline \multirow{3}{*}{ Pengetahuan } & \multicolumn{6}{|c|}{ Ibu Hamil } & \multirow{3}{*}{ ?'Hitung } & \multirow{3}{*}{$2_{\text {Tabel }}$} & \multirow{3}{*}{ Value } \\
\hline & \multicolumn{6}{|c|}{ Tidak Anemia Anemia } & & & \\
\hline & $\mathrm{N}$ & $\%$ & J & $\%$ & $\mathrm{~N}$ & $\%$ & & & \\
\hline Kurang & 11 & 2,9 & j & 2,5 & 17 & 5,4 & \multirow{4}{*}{.611} & \multirow{4}{*}{991} & \multirow{4}{*}{.013} \\
\hline Cukup & 7 & 4,6 & 3 & 8,8 & 16 & 3,3 & & & \\
\hline Baik & 14 & 9,2 & 1 & $!, 1$ & 15 & 1,2 & & & \\
\hline Total & 32 & 6,7 & 6 & 3,3 & 18 & 00 & & & \\
\hline
\end{tabular}

Sumber : Data primer (2017)

Tabel 8. Hubungan Sikap Ibu Hamil Dengan Anemia

\begin{tabular}{|c|c|c|c|c|c|c|c|c|c|}
\hline \multirow{3}{*}{ Sikap } & \multicolumn{4}{|c|}{ Ibu Hamil } & \multirow{2}{*}{\multicolumn{2}{|c|}{ - Total }} & \multirow{3}{*}{ 'Hitung } & \multirow{3}{*}{${ }^{2}$ Tabel } & \multirow{3}{*}{ Value } \\
\hline & \multicolumn{2}{|c|}{ Tidak Anemia } & \multicolumn{2}{|c|}{ Anemia } & & & & & \\
\hline & $\mathrm{N}$ & '́ & & $\%$ & $\checkmark$ & '́ & & & \\
\hline Negative & 12 & $! 5,0$ & 5 & $i 1,2$ & $! 7$ & 2 & & & \\
\hline Positif & 20 & $.1,7$ & 1 & 2,1 & $! 1$ & 8 & 3.71 & 0.991 & \\
\hline
\end{tabular}




\begin{tabular}{llllllll|l|l}
\hline Total & 32 & $i 6,7$ & 6 & $i 3,3$ & 18 & J & & & 000 \\
\hline
\end{tabular}

Sumber : Data primer (2017)

Berdasarkan hasil penelitian pada tabel 8 di dapatkan hasil ibu yang tidak anemia dan memiliki sikap negatif sebanyak 12 orang $(25,0 \%)$ dan sikap positif sebanyak 20 orang $(41,7 \%)$ serta ibu yang hamil yang anemia dan memiliki sikap negatif sebanyak 15 orang $(31,2 \%)$ dan sikap positif sebanyak 1 orang $(2,1 \%)$. Dalam hal ini mayoritas responden memiliki sikap negatif, hal ini mungkin disebabkan rendahnya pengetahuan ibutentang anemia serta tidak ada kesadaran dari ibu hamil untuk "memperhatikan kehamilan ibu sendiri dengan mengkonsomsi makanan bergizi guna untuk kesehatan ibu dan janin. Dari hasil analisis uji statistik SPSS 16 menggunakan rumus Chi-square dengan tingkat kemaknaan 0,05 diperoleh hasil $0.000<0,05$ yang berarti ada hubungan sikap dengan anemia di Wilayah Kerja Puskesmas Limboto Kabupaten Gorontalo.

\section{KESIMPULAN DAN SARAN}

1. Dari hasil penelitian diperoleh tingkat pengetahuan kurang ibu hamil sebanyak 17 responden $(35,4 \%)$, pengetahuan cukup sebanyak 16 orang $(33,3 \%)$, dan pengetahuan baik sebanyak 15 orang $(31,2 \%)$.

2. Dari hasil penelitian bahwa mayoritas sikap ibu hamil yaitu sikap negatif terhadap pencegahan anemia, dimana ibu hamil tidak mengkonsumsi tablet Fe serta tidak mengkonsumsi makanan yang bergizi sebanyak 27 orang $(56,2 \%)$ dan ibu hamil yang memiliki sikap positif terhadap pencegahan anemia sebanyak 21 orang (43,8\%), dimana ibu hamil mengonsumsi tablet $\mathrm{Fe}$ dan mengonsumsi makan yang mengandung zat besi.

3. Dari hasil penelitian diperoleh bahwa ada hubungan pengetahuan dengan anemia di Wilayah Kerja Puskesmas Limboto Kabupaten Gorontalo dengan $p$ value $0.013<0,05$.

4. Dari hasil penelitian diperoleh bahwa ada hubungan sikap dengan anemia di Wilayah Kerja Puskesmas Limboto Kabupaten Gorontalo dengan p value $0.000<$ 0,05 .

\section{Saran}

Bagi ilmu pengetahuan

Di harapkan penelitian ini dapat menambah wawasan ilmu pengetahuan tentang anemia, khususnya anemia pada ibu hamil.

Bagi peneliti

Diharapkan penelitian ini dapat menambah ilmu pengetahuan peneliti yang telah diperoleh di 
institusi pendidikan yaitu metologi penelitian dan statitistik kesehatan serta dapat menambah pengalaman peneliti dalam penelitian kesehatan khususnya tentang anemia pada ibu hamil. Serta dapat mengembangkan penelitian selanjutnya tentang perlaku, pendidikan, dan sosial ekonomi

Bagi institusi Pendidikan

Diharapkan penelitian ini dapat menjadi bahan bacaan dan untuk menambah wawasan bagi mahasiswa lain khususnya mengenai tingkat pengetahuan dan sikap ibu hamil primigravida tentang anemia.

Bagi Pelayanan Puskesmas

Diharapkan penelitian ini dapat dijadikan sebagai bahan masukan bagi puskesmas tentang pentingnya pengetahuan tentang anemia bagi ibu hamil khususnya ibu hamil primigravida.

\section{DAFTAR PUSTAKA}

Angrainy, R (2017). Hubungan Pengetahuan Dengan Sikap Ibu Hamil Dalam Pencegahan Anemia Di Puskesmas Rumbai. Journal Endurance. 2 (1) 62-67. Astuti.D (2016). Faktor Yang Berhubungan Dengan Kejadian Anemia Pada Ibu Hamil Di Puskesmas Undaan Lor Kabupaten Kudus

Dewi. R. K (2016). Pengaruh Konsumsi Buah Pisang Ambon Terhadap Anemia Pada Ibu Hamil Trimster 1 Di Wilyah Kerja Puskesmas Balowerti
Tahun 2016. Jurnal IImu Kesehatan Makia. 4 (1) 14-18 Dinas Kesehatan Kabupaten Gorontalo. 2016. Gorontalo

Kartikasari. M.N.D. 2010. Hubungan Antara Pengetahuan Dan Sikap Tentang Anemia Dengan Keteraturan Mengkonsumsi Fe Pada Ibu Hamil Di Bps Sri Lumintu Surakarta. Universitas Sebelas Maret. Surakarta.

Notoatmodjo S. 2012. Metodologi Penelitian Kesehatan. Jakarta ;PT. Rineka Cipta.

Prawirohardjo. S. 2014. IImu Kebidanan. Jakarta :PT Bina Pustaka Sarwono Prawirohardjo.

Wedyareni. A.R., Bambang, W dan Fitria H.P (2015). Faktor-Faktor Penyebab Anemia Pada Kehamilan Trimester lii Di Bpm Ny.Anik Kecamatan Barat Kabupaten Magetan.Maternal. 12 Edisi 78-85.

Yuwono.T.A. 2013.Hubungan

Dukungan Suami Terhadap Konsumsi Tablet FeDengan Kejadian Anemia Pada Ibu Hamil Di Puskesmas Ngampilan Kota Yogyakarta Tahun 2013.Sekolah Tinggi Ilmu Kesehatan 'Aisyiyah Yogyakarta. Skripsi. 



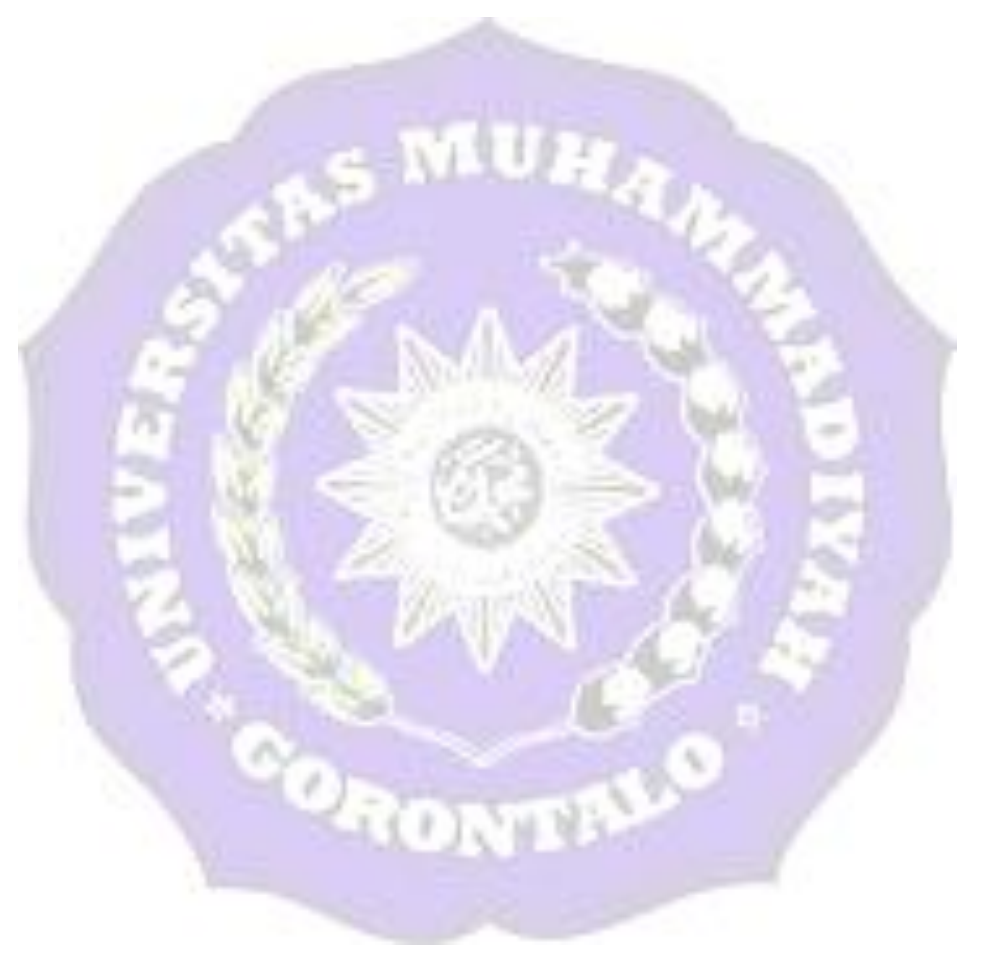

